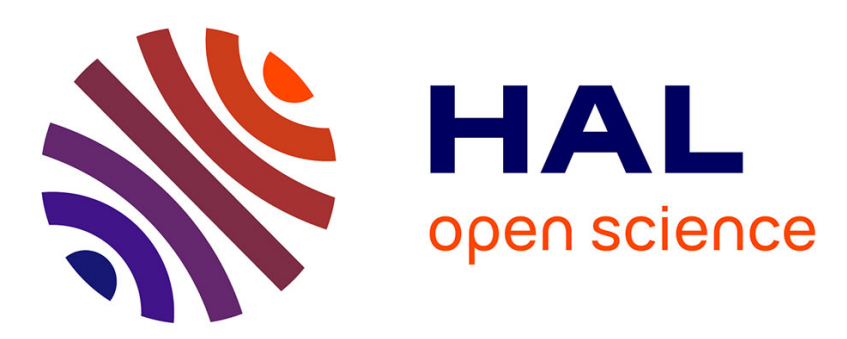

\title{
Endogenous discounting via wealth, Twin-Peaks and the role of technology
}

Ingmar Schumacher

\section{To cite this version:}

Ingmar Schumacher. Endogenous discounting via wealth, Twin-Peaks and the role of technology. 2009. hal-00356233

\section{HAL Id: hal-00356233 \\ https://hal.science/hal-00356233}

Preprint submitted on 27 Jan 2009

HAL is a multi-disciplinary open access archive for the deposit and dissemination of scientific research documents, whether they are published or not. The documents may come from teaching and research institutions in France or abroad, or from public or private research centers.
L'archive ouverte pluridisciplinaire HAL, est destinée au dépôt et à la diffusion de documents scientifiques de niveau recherche, publiés ou non, émanant des établissements d'enseignement et de recherche français ou étrangers, des laboratoires publics ou privés. 


\section{ECOLE POLYTECHNIQUE}

CENTRE NATIONAL DE LA RECHERCHE SCIENTIFIQUE

\section{ENDOGENOUS DISCOUNTING VIA WEALTH, TWIN-PEAKS AND THE ROLE OF TECHNOLOGY}

Ingmar SCHUMACHER

January 2009

Cahier $n^{\circ}$ 2009-03

\section{DEPARTEMENT D'ECONOMIE}

Route de Saclay

91128 PALAISEAU CEDEX

(33) 169333033

http://www.enseignement.polytechnique.fr/economie/

mailto:chantal.poujouly@polytechnique.edu 


\title{
Endogenous Discounting via Wealth, Twin-Peaks and the Role of Technology
}

\author{
Ingmar Schumacher ${ }^{1}$ \\ Ecole Polytechnique, Paris
}

January 23, 2009

\begin{abstract}
We endogenize the discount rate via wealth and provide evidence that wealth affects the discount rate negatively. We give a necessary and sufficient condition for endogenous discounting to lead to the Twin-Peaks of economic growth and show that improvements in technology help avoid them.

JEL classification: D90, C61, O41.

Keywords:endogenous discounting, Twin-Peaks of economic growth, multiple equilibria.
\end{abstract}

\section{Introduction}

We are becoming more and more aware that convergence between country's income levels is far from obvious. Empirical observations have forcefully shown that rich countries are becoming richer, while poor ones are not able to catch up. Jones [14], Azariadis [1] and Quah [21] find that the world income distribution changed from a somewhat normal distribution shape toward a twin-peak shape. We provide new answers to the following two questions: One, what can be a potential source of these twin-peaks? Two, why were some of the countries that were believed to belong to the group of low steady state countries (like Taiwan, South Korea) able to reach a convergence path which led them to a high steady state?

Theoretical models have attempted to draw some conclusions on the possible sources of these twin-peaks of economic growth. These models have either built on non-convexities in technologies to arrive at multiple steady states (Azariadis and Drazen [2]) or on incomplete markets (Durlauf [8]; Quah [21]).

In this article we propose endogenous discounting as another potential source of the twin-peaks of economic growth. Specifically, we argue that wealth affects the discount rate by proposing that this is a shortcut for suggesting that wealthier countries have better health standards (Pritchett [20]) and better insurance markets (Carroll [4]), all of which generally affects the agent's discount rate negatively (Frederick et al. [12]).

There exist now an increasing number of endogenous discounting models, which nearly exclusively have consumption as the source of endogenity (e.g. Epstein and Hynes [9]; Obstfeld [17]; Das [5]). In a recent working paper, Drugeon [7] allows for consumption and capital to influence the discount rate, but focuses on increasing returns in the production function and does not provide a thorough analysis of multiple steady states.

Our treatment of wealth here will be based upon a broad view of wealth combining physical capital and human capital (see Mankiw [15]). Fielding and Torres [11] estimate the relationship between wealth, health and education for 41 developing countries. They find that improvements in physical and human wealth lead to lower mortality rates. Their results are robust even across countries, pointing at a uniform effect of the variables in question. Similar

\footnotetext{
${ }^{1}$ Department of Economics, Ecole Polytechnique, 91128 Palaiseau Cedex, France. email: ingmar.schumacher@ polytechnique.edu, tel: 0033169333038.

The author is grateful for helpful comments by Raouf Boucekkine. Financial support from the Chaire Lhoist Berghmans in Environmental Economics in CORE and from the Chair AXA Assurance et Risques Majeurs at the Ecole Polytechnique is kindly acknowledged. This article was mostly written during my stay in CORE. Any errors lie with the author.
} 
results are due to Grossman [13], Feldman et al. [10], Pappas et al. [18], Preston and Elo [19], Richards and Barry [22]. Wealth as a source of endogenous discounting has also been proposed by Becker and Mulligan [3] as well as Deaton and Paxson [6], who show that financial assets and human capital inequality grow as cohorts age. These results are interpreted by Becker and Mulligan [3] as a potential consequence of endogenous time preference.

We derive a necessary and sufficient condition for the existence of multiple steady states and show that discounting endogenized via wealth can provide another explanation for the development of the twin-peaks of economic growth. We believe this is a particular useful extension as existing contributions to the literature on twin-peaks exhaustively focus on the twin-peaks as a result of assumptions on technologies or uncertainty. Here, however, the twin-peaks arise through the preferences of the agents.

We answer our second question by demonstrating how improvements in technology can help avoid the twinpeaks. This result ought to be particularly interesting for the case of developing countries.

\section{The Model}

The model is based on an infinitely-lived agent approach where the agent obtains utility $u(\cdot)$ from consumption $c(t)$. In addition, his wealth $k(t)$ affects the discount rate $\rho(k(t))$ negatively. Wealth can be accumulated by investing but is reduced by consumption and constant depreciation $\delta>0$. The infinitely-lived agent then solves the following problem.

$$
\max _{\{c(t)\}} U(c, k)=\int_{t=0}^{\infty} u(c(t)) e^{-\theta(t)} d t \quad \text { s.t. } \begin{cases}\dot{k}(t)=f(k(t))-c(t)-\delta k(t), & \forall t \\ \dot{\theta}(t)=\rho(k(t)), & \forall t \\ k(t) \geq 0, c(t) \geq 0, & \forall t, \\ \text { with } k(0) \text { given. } & \end{cases}
$$

We make use of the following assumptions.

(A1) We impose that the production function $f: \mathbb{R}_{+} \rightarrow \mathbb{R}_{+}$follows standard assumptions of concavity, such that $f(k) \geq 0, f(0)=0, f^{\prime}(k)>0, f^{\prime \prime}(k)<0$, with $\lim _{k \rightarrow 0} f^{\prime}(k)=\infty$, and $\lim _{k \rightarrow \infty} f^{\prime}(k)=0$. We define $\bar{k}$ as the level of $k$ which solves $f(k)=\delta k$, and $k$ as the level of $k$ that solves $f^{\prime}(k)=\delta$.

(A2) The utility function $u: \mathbb{R}_{+} \rightarrow \mathbb{R}_{+}$is at least twice continuously differentiable with $u^{\prime}(c)>0, u^{\prime \prime}(c)<0, \forall c$, and $\lim _{c \rightarrow 0} u^{\prime}(c)=\infty$.

(A3) We take $\rho(k): \mathbb{R}_{+} \rightarrow \mathbb{R}_{+}$with $\rho^{\prime}(k)<0$ and $\rho^{\prime \prime}(k)>0$, where we impose $\lim _{k \rightarrow \infty} \rho(k)>0$.

This model generalizes the neoclassical Ramsey-Caas-Koopmans model by introducing a discount rate endogenized via wealth. It reduces to the classical model if we assume that $\rho(k(t))=r, \forall t$. Integrating $\dot{\theta}=\rho(k(t))$ from $t \in[0, \tau]$ then leads to $\theta(\tau)=r \tau$. Substituting this into (1) gives the classical model.

\subsection{Solving the Model}

We define the value function

$$
V(k)=\max _{\{c\}} U(c, k) \text { s.t. } \dot{k}=f(k)-c-\delta k, k(0)>0 \text { given, }
$$

which leads to the following Bellman equation

$$
0=\max _{c}\left\{u(c)-\rho(k) V(k)+V^{\prime}(k) \dot{k}\right\} .
$$

The first order conditions are

$$
u^{\prime}(c)=V^{\prime}(k) .
$$

By equation (4) we can write $c(k)$, substituting this in (3) gives

$$
0=-\rho^{\prime}(k) V(k)+V^{\prime \prime}(k) \dot{k}+V^{\prime}(k)\left(f^{\prime}(k)-\delta-\rho(k)\right) .
$$


We know that $V^{\prime}(k)=\lambda$, with $\lambda$ being the shadow price of capital. Also, $V^{\prime \prime}(k) \dot{k}=\frac{\partial V^{\prime}(k)}{\partial k} \frac{\partial k}{\partial t}$, implying $V^{\prime \prime}(k) \dot{k}=$ $\dot{\lambda} . V(k)$ is the prospective optimal value of utility. Rewriting leads to the following system

$$
\begin{aligned}
\dot{c} & =-\frac{u^{\prime}(c)}{u^{\prime \prime}(c)}\left[f^{\prime}(k)-\delta-\rho(k)-\frac{\rho^{\prime}(k)}{\rho(k)}\left(\frac{u(c)}{u^{\prime}(c)}+\dot{k}\right)\right], \\
\dot{k} & =f(k)-c-\delta k .
\end{aligned}
$$

The last term of equation (6) is obtained by making use of the correspondence between first-order conditions from the Hamiltonian method and the Bellman method as well as using Michel's [16] transversality condition. That this correspondence indeed holds is because the conditions from Stokey and Lucas [24], are satisfied. For $\rho^{\prime}(k)=0$ we see that equation (6) reduces to the Keynes-Ramsey rule of optimal consumption.

We define $m(k)=\frac{\rho^{\prime \prime}(k) \rho(k)-\rho^{\prime}(k)^{2}}{\rho(k)^{2}}$ with $m(k) \gtrless 0$, and $n(k)=\frac{u^{\prime}(c)^{2}-u^{\prime \prime}(c) u(c)}{u^{\prime}(c)^{2}}>0$.

Proposition 1 A necessary and sufficient condition for multiple steady states ${ }^{1}$ is $\exists k>0$ such that

$$
f^{\prime \prime}(k)>(1+n(c)) \rho^{\prime}(k)+m(k) \frac{u(c)}{u^{\prime}(c)}+\frac{\rho^{\prime}(k)^{2}}{\rho(k)^{2}} n(c) \frac{u(c)}{u^{\prime}(c)},
$$

with $c=f(k)-\delta k$.

In a standard Ramsey-Caas-Koopmans model with a concave production function this condition will never be satisfied since the right-hand side of equation (8) will be equal to zero. We denote the steady states as $0<k^{l}<$ $k^{m}(<\tilde{k})<k^{h}(<\bar{k})$. When one linearizes the dynamical system around the non-trivial steady states, $\left\{c^{l}, k^{l}\right\}$,

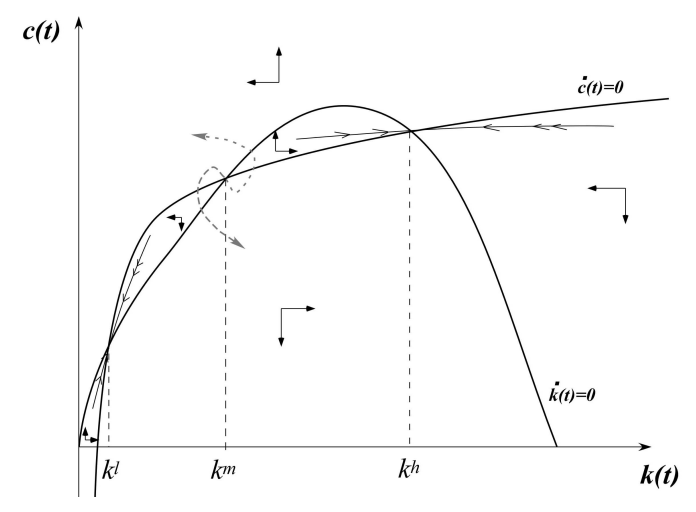

Figure 1

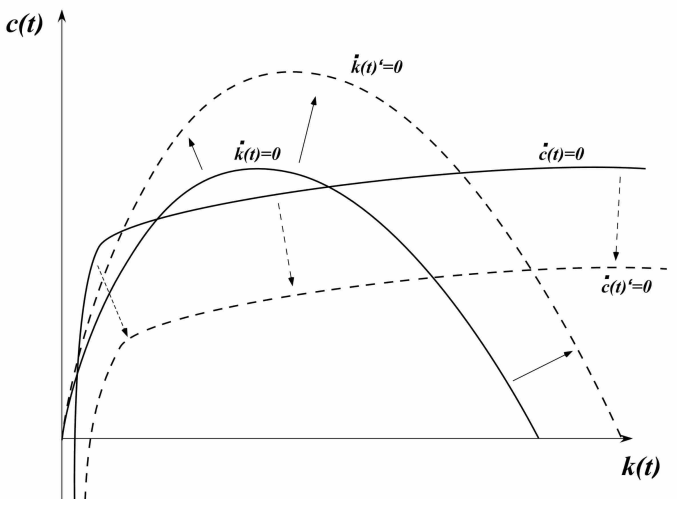

Figure 2

$\left\{c^{m}, k^{m}\right\}$ and $\left\{c^{h}, k^{h}\right\}$, one gets the following differential system:

$$
J=\left[\begin{array}{cc}
\rho(k)+\delta-f^{\prime}(k) & -\frac{u^{\prime}(c)}{u^{\prime \prime}(c)}\left(f^{\prime \prime}(k)-\rho^{\prime}(k)-m(k) \frac{u(c)}{u^{\prime}(c)}-\left(f^{\prime}(k)-\delta\right) \frac{\rho^{\prime}(k)}{\rho(k)}\right) \\
-1 & f^{\prime}(k)-\delta
\end{array}\right] .
$$

As the trace is $\operatorname{Tr}(J)=\lambda_{1}+\lambda_{2}$, and the determinant is $\operatorname{Det}(J)=\lambda_{1} \lambda_{2}$, with $\lambda_{1}$ and $\lambda_{2}$ denoting the eigenvalues of the Jacobian, saddle-path stability occurs if the trace is positive and the determinant is negative. The trace of this matrix is given by $\operatorname{Tr}(J)=\rho(k)>0$, while the determinant is negative if

$$
f^{\prime \prime}(k)<\rho^{\prime}(k)+m(k) \frac{u(c)}{u^{\prime}(c)}+\frac{\rho^{\prime}(k)}{\rho(k)}\left(f^{\prime}(k)-\delta\right) n(k) .
$$

From the conditions for multiple equilibria we know that this condition does not hold for the middle steady state, which is thus instable. It holds for the low and high steady states, which implies saddle path stability. Complex

\footnotetext{
${ }^{1}$ The case of unique steady state has been treated in Schumacher [23].
} 
dynamics arise if $\operatorname{Tr}(J)^{2}<4 \operatorname{Det}(J)$. As $\operatorname{Det}(J)<0$ for the low and high steady state, this excludes the possibility of complex dynamics for these steady states. However, for the medium steady state complex dynamics occur if $\rho(k)^{2}<-4 \frac{u^{\prime}(c)}{u^{\prime \prime}(c)}\left(f^{\prime \prime}(k)-\rho^{\prime}(k)-m(k) \frac{u(c)}{u^{\prime}(c)}-n(k) \frac{\rho^{\prime}(k)}{\rho(k)}\left(f^{\prime}(k)-\delta\right)\right)$. This corresponds to the recent twin-peaks of economic growth hypothesis raised by researchers like Quah [21], Jones [14] and Azariadis [1] and is depicted in Figure 1.

In order to understand where the multiplicity of equilibria comes from we re-write equation (6) by solving for $V(k)$, which gives

$$
\dot{c}(t)=-\frac{u^{\prime}(c(t))}{u^{\prime \prime}(c(t))}\left[f^{\prime}(k(t))-\delta-\rho(k(t))-\frac{\rho^{\prime}(k(t)) \int_{t}^{\infty} u(c(s)) e^{-\theta(s)} d s}{u^{\prime}(c(t))}\right]
$$

The multiplicity of steady states occurs since when an agent is very poor then increases in consumption are necessary for survival $\left(u^{\prime}(0)=\infty\right)$, and the agent is so impatient that the preferences are nearly exclusively directed toward today, implying that most wealth will be directly consumed. Similarly, if the future expected utility is very low, then our agent will prefer to consume current wealth. For $k>k^{m}$ however, this implies that overall wealth has already been built up sufficiently in order to incorporate far-sighted goals, such that the discount rate is relatively low (or the life expectancy high enough). For example, with a low enough mortality rate agents will need to carefully plan ahead to the distant future, whereas a high mortality rate implies that agents don't expect to become old and thus do not plan ahead. If we use Stone-Geary preferences to analyze the impact of changes in the subsistence level of consumption, then we find that increases in the subsistence level decrease the last term in equation (11). This means that the higher the subsistence level or the closer is consumption to subsistence the less willing are agents to postpone consumption and the less important becomes the impact of wealth on the discount rate. In other words, consumption close to subsistence and a low expected future utility, both a likely phenomena in less developed countries, are likely to trap countries in the low wealth equilibrium.

One can easily show that improvements in total factor productivity lead to shifts in the steady state curves as depicted in Figure 2. The intuition is that if wealth is more productive, then it is more efficient to increase the level of wealth in order to raise overall utility by reducing the discount rate. In recent years, some of the countries that were believed to belong to the group of low steady state countries (South Korea, Taiwan, etc.) were able to reach a convergence path which led them to a high steady state. It is plausible that this is due to improvements in technology or health (mortality). This should provide a new and interesting possibility for policy interventions which focus on international convergence of wealth.

\section{References}

[1] C. Azariadis. The economics of poverty traps part one: Complete markets. Journal of Economic Growth, 1(4):449-486, 1996.

[2] C. Azariadis and A. Drazen. Threshold Externalities in Economic Development. The Quarterly Journal of Economics, 105(2):501-526, 1990.

[3] Gary S Becker and Casey B Mulligan. The endogenous determination of time preference. The Quarterly Journal of Economics, 112(3):729-58, August 1997.

[4] Christopher D Carroll. Buffer-stock saving and the life cycle/permanent income hypothesis. The Quarterly Journal of Economics, 112(1):1-55, February 1997.

[5] Mausumi Das. Optimal growth with decreasing marginal impatience. Journal of Economic Dynamics and Control, 27(10):1881-1898, August 2003.

[6] A. Deaton and C. Paxson. Intertemporal Choice and Consumption Inequality. Journal of Political Economy, 102:437-467, 1994. 
[7] J.-P. Drugeon. A Propelling Role for Impatience in Long-Run Growth. Technical report, unpublished document, 2001.

[8] S.N. Durlauf. Nonergodic Economic Growth. The Review of Economic Studies, 60(2):349-366, 1993.

[9] Larry G Epstein and J Allan Hynes. The rate of time preference and dynamic economic analysis. Journal of Political Economy, 91(4):611-35, August 1983.

[10] J.J. Feldman, D.M. Makuc, J.C. Kleinman, and J. Cornoni-Huntley. National trends in educational differentials in mortality. American Journal of Epidemiology, 129(5):919-933, 1989.

[11] D. Fielding and S. Torres. Health, Wealth, Fertility, Education and Inequality. Technical report, University of Otago Economics Discussion Papers, 2005.

[12] Shane Frederick, George Loewenstein, and Ted O'Donoghue. Time discounting and time preference: A critical review. Journal of Economic Literature, 40(2):351-401, 2002.

[13] M Grossman. Education and nonmarket outcomes. In E. Hanushek and F. Welch, editors, Handbook of the Economics of Education. Amsterdam, North-Holland, Elsevier, 2003.

[14] Charles I Jones. On the evolution of the world income distribution. Journal of Economic Perspectives, 11(3):19-36, 1997.

[15] Gregory N. Mankiw. The growth of nations. NBER Reprints 1999, National Bureau of Economic Research, Inc, 1995.

[16] Philippe Michel. On the transversality condition in infinite horizon optimal problems. Econometrica, 50(4):975-85, July 1982.

[17] Maurice Obstfeld. Intertemporal dependence, impatience, and dynamics. Journal of Monetary Economics, 26(1):45-75, August 1990.

[18] G. Pappas, S. Queen, W. Hadden, and G. Fisher. The increasing disparity in mortality between socioeconomic groups in the united states, 1960 and 1986. New England Journal of Medicine, 329:103-109, 1993.

[19] S.H. Preston and I.T. Elo. Are Educational Differentials In Mortality Increasing in the United States? Journal of Aging and Health, 7(4):476-96, 1995.

[20] L. Pritchett and L.H. Summers. Wealthier is Healthier. The Journal of Human Resources, 31(4):841-868, 1996.

[21] Danny T Quah. Twin peaks: Growth and convergence in models of distribution dynamics. Economic Journal, 106(437):1045-55, 1996.

[22] H. Richards and R. Barry. US Life Tables for 1990 by Sex, Race, and Education. Journal of Forensic Economics, 11(1), 1998.

[23] I. Schumacher. Endogenous discounting and the domain of the felicity function. Technical report, CORE Discussion Paper No. 2006/103, 2006.

[24] N.L. Stokey, R.E. Lucas, and E.C. Prescott. Recursive methods in economic dynamics. Harvard University Press Cambridge, 1989. 